\title{
A METÁFORA DA DISCRIMINAÇÃO E DESIGUALDADE SOCIAL EM OLHOS D'ÁGUA
}

\author{
Denise Velasco* \\ Marcelo Saparas ${ }^{* *}$
}

\begin{abstract}
RESUMO: O presente trabalho é um recorte de uma pesquisa de mestrado que busca verificar/analisar as escolhas linguisticas encontradas na narrativa do conto "Maria" da obra Olhos d'água de Conceição Evaristo. Nessas escolhas observa-se discriminação, desigualdade e preconceito racial. Na análise do conto foram utilizados aspectos teóricos da Linguística Sistêmico Funcional (HALLIDAY, 1994), por meio da metafunção interpessoal, que revelam a forma como os personagens, por meio de suas escolhas lexicogramaticais, constroem os/seus textos. Por meio da Avaliatividade (MARTIN e WHITE, 2005) notase que seu sistema possibilita a construção de parâmetros que contribuem para uma análise mais clara sobre as relações entre posicionamento (criticidade) e conhecimento linguístico, envolvidos nas questões raciais. Nesse percurso investigativo, as avaliações referem-se ao posicionamento dos participantes do conto, feitos léxico-gramaticalmente. Segundo Halliday (1985), a língua apresenta-se como um sistema semiótico, construído pela construção de significados baseados em escolhas linguísticas considerando-se o contexto. Essas escolhas representam o meio pelo qual percebemos sinais de ressignificação no discurso/narrativa do conto. Justifica-se, desse modo, a inserção da Avaliatividade (Martin, 2000) como elemento norteador da análise do conto em questão. Considerar-se-á também a metáfora conceptual (LAKOFF e JOHNSON, 1980), que traz em seu bojo a observação dos aspectos da cognição, da linguagem, do pensamento e do comportamento humano, que servirá de embasamento teórico para análises dos textos da obra. A análise do capitulo "Maria" mostra um linchamento da personagem principal, que ocorre devido a preconceito pela desigualdade social e racismo. Das escolhas lexicais, por meio da avaliatividade, levando em conta o frame do leitor, revela-se a metáfora NEGRITUDE É CULPABILIDADE.
\end{abstract}

ABSTRACT: The present investigation is an excerpt from a master's research that seeks to verify/analyze the linguistic choices presented in the narrative in the short story "Maria" from the book Olhos d'água by Conceição Evaristo that lead us to observe discrimination, inequality and racial prejudice. For this purpose, theoretical aspects of Systemic Functional Linguistics (HALLIDAY, 1994) were used, through the interpersonal metafunction, which investigates how the characters, through their lexical choices, build their texts. Through Appraisal (MARTIN and WHITE, 2005), it's known its system can enable the construction of parameters that contribute to a clearer analysis of the relationships between positioning (criticality) and linguistic knowledge involved in racial issues. In this investigation, the evaluations refer to the positioning of the participants in the short story, made lexicogrammatically. According to Halliday (1985), language presents itself as a semiotic system built by meanings based on linguistic choices considering context. These choices represent the means by which we perceive signs of resignification in the discourse/narrative of the short story. Thus, the inclusion of Appraisal (Martin, 2000) as a guiding element in the analysis of the story in question is justified. The conceptual metaphor will also be considered (LAKOFF and JOHNSON, 1980), as it brings in the observation of aspects of cognition, language, thought and human behavior, which will serve as a theoretical basis for the analysis of the texts of the research. The analysis of the chapter Maria shows a lynching of the main character, which occurs due to prejudice, social inequality and racism. From the lexical choices, through appraisal, taking into account the reader's frame, the metaphor NEGRITY IS GUILTY is revealed.

PALAVRAS-CHAVE: Discriminação, Desigualdade, Metáfora, Literatura.

KEYWORDS: Discrimination. Inequality. Metaphor. Literature.

INTERLETRAS, ISSN N $N^{\circ}$ 1807-1597. V. 9, Edição número 34. Outubro, 2021/ Março de 2022- p.

Dossiê: Estudos de indigenismo, negritude e miscigenação: o (des)cobrimento, colonização e o agora(?). 


\section{INTRODUÇÃO}

Esta pesquisa tem uma abordagem interdisciplinar da confluência das áreas de linguística e literatura, fazendo, assim, uma análise linguística da microestrutura do texto da obra Olhos d'Água, e tem como objetivo entender a macroestrutura textual relacionada a postura ideológicas, via metáfora, construídas a partir das escolhas lexicais encontradas na microestrutura dos contos. Para tanto, ela procura responder às seguintes perguntas:

(a) Que escolhas gramaticais confirmam o racismo, discriminação e desigualdade?

(b) Que papel exerce a avaliatividade e a metáfora nesse processo?

\section{Racismo, desigualdade, discriminação}

O Brasil ocupa uma posição de destaque no mundo e, por muito, tempo tem sido considerado como um país em que não se apresenta segregação racial formalizado e estabelecido, porém a realidade se mostra dura e cruel em que à desigualdade e a discriminação racial são pungentes, perceptíveis para pessoas negras e com árduas e preocupantes consequências para o contingente afro-brasileiro e a sociedade como um todo.

As desigualdades se estendem por todas as fases da vida dos indivíduos da infância à velhice, na educação, na saúde, na moradia e no mercado de trabalho com diferença salarial e na ocupação de cargos dentro das instituições, na vida social e cultural, no comprometimento do seu entendimento como cidadão que possui direitos e na sua totalidade de sua vida. A inserção/integração efetiva das pessoas negras na sociedade seria uma oportunização para a elaboração constitucional de um país verdadeiramente democrático e com chances igualitárias para todos.

Essas questões sociais são assuntos presentes nas narrativas de diversos escritores/autores de obras literárias com diferentes enfoques e abordagens. Como autores engajados nessas questões sociais e contemporâneas temos Conceição Evaristo.

A autora e escritora Conceição Evaristo nasceu em 29 de novembro de 1946 em uma comunidade nos Altos da Avenida Afonso Pena em Belo Horizonte. Com oitos anos começou dentre um dos ofícios da família (mãe e tias) seu primeiro emprego: empregada doméstica e surgiram outros. Uma família formada por empregadas domésticas.

Em 1973, após passar num concurso público para o magistério mudou-se para o Rio de janeiro, onde trabalhou como professora da rede pública de ensino na qual lecionava em uma escola em Niterói (região metropolitana do Rio de janeiro) e, simultaneamente, em outra no município no Rio de Janeiro. Fez graduação no curso de Letras na Universidade Federal do Rio de Janeiro (UFRJ), concluiu seu mestrado em Literatura Brasileira na Pontifícia Universidade Católica do Rio de Janeiro (PUC/RJ) no qual defendeu a dissertação "Literatura Negra: uma poética da nossa afro-brasileira". Seu doutorado foi

INTERLETRAS, ISSN No 1807-1597. V. 9, Edição número 34. Outubro, 2021/ Março de 2022- p.

Dossiê: Estudos de indigenismo, negritude e miscigenação: o (des)cobrimento, colonização e o agora(?) . 
em Literatura Comparada com "Poemas Malungos - Cânticos Irmãos" no ano de 2011 e foi realizado na Universidade Federal Fluminense (UFF).

Dentre todas as obras dessa notável escritora contemporânea, compromissada com a cultura negra, este trabalho dá ênfase à obra "Olhos d'água" (2014) que legitimiza Conceição Evaristo no campo literário brasileiro. É um livro de contos que reúne 15 contos do cotidiano de indivíduos que buscam resistir às mazelas de uma sociedade que traz consigo profundas desigualdades sociais, raça e gênero. Na narrativa estão presentes mulheres negras que pertencem e dividem a mesma dor e luta. $\mathrm{O}$ conto que nomeia a obra dita o caminho para qual o livro se dirige, em que a narradora tem o sentimento de angústia por tentar lembrar-se da cor dos olhos de sua mãe. Através de seus pensamentos e sentimentos, ela retorna à sua infância junto à mãe e às irmãs que dividiam as experiências, momentos de alegria, pobreza e vulnerabilidade social com a presença constante do medo.

\section{Conexões entre Língua e Literatura}

A área compartilhada entre os estudos linguísticos e estudos literários podem ser apreciadas de forma harmônica e com a possibilidade de valorização de ambas, sem que elas percam ou tenham suas particularidades ofuscadas uma perante a outra, sem colocálas frente à dicotomia entre língua e literatura, entre linguagem e vida, entre uso e criatividade, entre gramática estilística.

Segundo Brait (2013), esse olhar em textos literários e poéticos podem ser capazes de ser alcançados pela temática e/ou pela organização na afluência entre língua e literatura, esferas de expressão e de conhecimento. Para se observar esses domínios, a literatura e a escrita e seus diversos estilos se manifestam através de uma comoção, proporcionando ao leitor contatar e vivenciar sentimentos de amor, ódio, surpresa, simpatia, empatia, etc., com o que está escrito, ou seja, o escritor se utiliza de recursos linguísticos para cativar o leitor e fazê-lo mergulhar no universo criado/estruturado para o entendimento e a compreensão dos caminhos para os quais ele deseja conduzi-lo nos diferentes estilos de texto. Para cada composição de escrita existe uma estratégia, pois ao se deparar com a estrutura da escrita, já se tem a percepção de como será possível proceder para compreensão da mensagem.

\section{APOIO TEÓRICO}

\subsection{A Linguística Sistêmico Funcional (LSF)}

A teoria da Sistêmico-Funcional se estrutura e adquire contribuições de países da Europa, Ásia, América Latina em sua abordagem e apresenta uma visão epistêmica em que observa a língua como um complexo linguístico interligado, onde é possível a elaboração de significados, na sua individualidade e são alternativas que podem ser categorizadas no campo da semântica, léxico-gramática ou fonologia e grafologia. Em sua funcionalidade

INTERLETRAS, ISSN N $N^{o}$ 1807-1597. V. 9, Edição número 34. Outubro, 2021/ Março de 2022- p.

Dossiê: Estudos de indigenismo, negritude e miscigenação: o (des)cobrimento, colonização e o agora(?) . 
esclarece as estruturas gramaticais vinculando o significado e as funções da linguagem ao texto.

$\mathrm{Na}$ visão sistêmico-funcional a linguagem é um instrumento de integração social do indivíduo com o qual há favorecimento, de forma regrada, a sua atuação social em diferentes papéis dentro do seu contexto, que por sua vez, está dentro de um sistema semiótico que se orienta pela gramática e como tal, a linguagem se concretiza através dos textos.

O contexto de situação mencionado por Halliday (1989, p.12) apresenta variáveis: campo (atividade desenvolvida pelos participantes/elementos, sua ação social e objetivo específico), as relações (papel desempenhado, controle exercido sobre eles, distância social/grau de formalidade, variação da frequência de interação) e o modo (função exercida pela linguagem ao veículo utilizado, expectativa dos participantes para com determinada situação, compartilhamento dos participantes, do canal e do meio).

A identificação das variáveis contextuais de situação em determinados elementos linguísticos é realizada pelo fato das variáveis contextuais terem uma relação com as funções desempenhadas pela linguagem que são nomeadas por Halliday (1994) como as metafunções.

As metafunções são as expressões, no sistema linguístico, que se mostram no uso da língua: compreensão do meio, relação interpessoal, organização de informações que se conectam a uma variável do contexto de situação. Essas metafunções da linguagem se estabelecem na oração como unidade gramatical plurifuncional, que é formada através dos significados ideacionais, interpessoais e textuais e pode ser observada como uma composição que cada uma possui de seu sistema no estrato léxico-gramatical.

Sendo assim a oração é estruturada com os significados ideacionais, interpessoais e textuais e uma estruturação de exposição e associações ordenadas como mensagem. A oração, parte principal de análise, é reconhecida pelo grupo verbal e pelo grupo nominal e a reunião de duas ou mais, que formam um complexo oracional e se conectam com a parte léxico-gramatical de uma língua.

\subsection{Avaliatividade}

Nesta investigação, as avaliações referem-se ao posicionamento das participantes no conto, feitas léxico-gramaticalmente. Segundo Halliday (1985), a língua apresenta-se como um sistema semiótico construído pela formação de significados baseados em escolhas linguísticas considerando-se o contexto. Essas escolhas representam o meio pelo qual percebemos sinais de ressignificação no discurso/narrativa do conto. Justifica-se, desta forma, a inserção da Avaliatividade como elemento norteador da análise do conto em questão.

INTERLETRAS, ISSN N $N^{o}$ 1807-1597. V. 9, Edição número 34. Outubro, 2021/ Março de 2022- p.

Dossiê: Estudos de indigenismo, negritude e miscigenação: o (des)cobrimento, colonização e o agora(?) . 
A Avaliatividade está fundamentada na linguística Sistêmico-Funcional, e também na avaliação da linguagem, como proposto por outros autores (MARTIN, 2004).

A Avaliatividade se subdivide em três campos de interação: ATITUDE, ENGAJAMENTO e GRADAÇÃO. Cada campo é considerado por Martin (2004) como um campo de significados.

A ATITUDE, por exemplo, está relacionada a nossos sentimentos, incluindo reações emocionais, o AFETO, JULGAMENTO de nossos comportamentos e APRECIAÇÃO, a avaliação material ou de eventos/situações. O ENGAJAMENTO é baseado nas atitudes e vozes de opiniões dentro do discurso.

A GRADAÇÃO, preocupa-se com o grau da avaliação como, por exemplo, em: muito interessante. Dentro da esfera ATITUDE, já que os recursos são inerentemente graduáveis, segundo Vian Jr,

a GRADAÇÃO consiste em ajustar o grau de uma avaliação, o quão forte ou fraco o sentimento é. Este tipo de GRADAÇÃO recebe o nome de 'força'; suas realizações incluem intensificação, morfologia comparativa e superlativa, repetição e vários aspectos grafológicos e fonológicos (juntamente ao uso do léxico intensificado 'odiar' para não gostar). Os JULGAMENTOS de estima social abordam avaliações que podem levar a pessoa a ser elevada ou rebaixada socialmente, e classificam-se em termos de 'normalidade', 'capacidade' e 'tenacidade' (VIAN Jr., 2009).

\section{Estima e avaliação/sanção social positiva e negativa}

É uma classificação, dentro do JULGAMENTO, que abriga avaliações sem conotações legais ou morais. Os significados associados à estima social são divididos em: normalidade (a oposição entre normal e diferente), capacidade (capaz ou incapaz) e tenacidade (resoluto e titubeante).

Os significados vinculados à sanção social são: veracidade (confiável/não confiável) e propriedade (ético/não ético). Já no sistema de APRECIAÇÃO, as avaliações são classificadas em: reação (interessante / desinteressante), composição (harmônico/ desarmônico, consistente/inconsistente) e valor (valioso/não valioso).

Enquanto que no AFETO, segundo Martin, o foco está no avaliador, na APRECIAÇÃO, a atenção volta-se ao objeto da avaliação. Martin e White (2005) definem três tipos de APRECIAÇÃO:

reação, quando o objeto de algum modo chama a sua atenção; composição, em relação ao equilíbrio e à complexidade do que está sendo avaliado e por fim o valor, ou seja, o quão inovador e relevante o objeto/situação parece. Se pensarmos nesses tipos de APRECIAÇÃO em termos de perguntas, teríamos por exemplo: i) “isso mexeu comigo?/”eu gostei disso?" para a reação; ii) "isso

INTERLETRAS, ISSN N $N^{o}$ 1807-1597. V. 9, Edição número 34. Outubro, 2021/ Março de 2022- p.

Dossiê: Estudos de indigenismo, negritude e miscigenação: o (des)cobrimento, colonização e o agora(?). 
me parece bem elaborado?"/"foi difícil de entender?" para a composição em termos de equilíbrio e complexidade respectivamente, e iii) "isso valeu a pena?", para o valor. (MARTIN, 2004)

\subsection{A metáfora}

A metáfora é um recurso linguístico muito estudado e vem despertando interesses de muitos estudiosos ao longo do tempo por ser uma ferramenta de diálogo com ampla utilização na comunicação humana que auxilia no discurso para alcançar a atenção do interlocutor, enriquecer a mensagem, facilitar a transmissão e a expressividade de ideias e pensamentos para que os fatos a serem comunicados possam chegar ao seu destino de forma espontânea, de maneira implícita e/ou poética. Dos escritores de diferentes estilos da literatura poética ao jornalismo econômico, passando pelos políticos, muitos a utilizam e justificam o seu emprego no texto por trazer uma face mais rica, interessante, divertida e dando beleza e dinamismo ao mesmo tempo. A forma como ocorrer é de maneira implícita em que a palavra sai do contexto habitual e vai para contexto figurado/metafórico trazendo cumplicidade entre o falante/escritor e o ouvinte/leitor na vida cotidiana como forma de expressão e manifestação no modo como o indivíduo entende e percebe o mundo com riquezas de detalhes e uma enorme complexidade.

Com um conceito e um pensamento sobre uma perspectiva diferente sobre a metáfora, George Lakoff (linguista) e Mark I. Johnson (filósofo), ambos americanos, no final da década de 1970, formulam a metáfora conceptual que foi publicada na obra Metaphors We Live By, em 1980, que tem o sentido de "As metáforas do Cotidiano", e, com esse título o exemplar, orienta a teoria principal para

\footnotetext{
"[...] o ponto principal da teoria: vivemos de acordo com as metáforas que existem na nossa cultura: praticamente não temos escolha: se quisermos fazer parte da sociedade, interagir, ser entendido, entender o mundo etc., precisamos obedecer ("live by") às metáforas que nossa cultura nos coloca à disposição [...]." (SARDINHA, 2007, p. 30)
}

Esse pensamento apresenta o entendimento que para estarmos integrados na sociedade, precisamos usar metáforas que estão disponíveis e fazem parte da cultura.

Contudo existem diferentes vertentes entre os que se pautam na teoria da metáfora conceptual, como George Lakoff e Ray Gibbs e os que são tradicionais.

Os principais conceitos de Lakoff e Gibbs estão ancorados em

uma metáfora sistemática de um domínio de veículo que é uma formulação abstrata que resume uma série de metáforas linguísticas usadas por um indivíduo ou grupo de pessoas em determinado contexto. [...] as metáforas sistemáticas são grafadas em "caixa alta” (SARDINHA, 2007, p. 38).

INTERLETRAS, ISSN N $N^{o}$ 1807-1597. V. 9, Edição número 34. Outubro, 2021/ Março de 2022- p.

Dossiê: Estudos de indigenismo, negritude e miscigenação: o (des)cobrimento, colonização e o $\operatorname{agora}(?)$. 


\subsection{Metonímia}

No livro Metaphors We Live By, Lakoff e Johnson comunicam que a metonímia conceptual existe como um mecanismo conceitual, é central para o pensamento e a linguagem humana, se propõe na descrição e a interpretação de um fenômeno.

A metonímia como a metáfora são resultados de processos cognitivos e produzem significados, sendo um dispositivo linguístico, que pode ser entendido/analisado na linguagem diária fora do seu contexto habitual de figura de linguagem como um recurso que se utiliza de uma linguagem representativa que busca o entendimento de uma realidade e um conceito da relação em que "X representa $Y$ ", ou seja, uma entidade represente outra, pois os dois conceitos existem no mesmo domínio em uma relação estruturada na contiguidade ou "proximidade" conceitual, como por exemplo: CONTINENTE PELO CONTEÚDO, PARTE PELO TODO ou EFEITO PELA CAUSA.

\section{METODOLOGIA}

Trata-se de uma pesquisa de caráter qualitativo, que se caracteriza pela investigação e interpretação do autor que examina uma unidade cujos limites são esclarecidos em termos de respostas a perguntas feitas, de fontes de dados usadas, e do contexto envolvido. (HALLOWAY, 1997). A metodologia se baseia na gramática-da-oração para explicar como os elementos léxico-gramaticais da estrutura superficial do texto comunica, ideologias específicas e identidades no nível profundo do discurso dentro da abordagem da LSF de Halliday (1994). Entretanto, por se tratar de uma pesquisa dentro da área da linguística aplicada, cuja abordagem tende a ser eclética, empregando uma metodologia mista, utilizaremos também os estudos da linguística cognitiva, mais especificamente a metáfora e a metonímia, que serão o foco da pesquisa.

Para análise será considerada a logogênese textual, que implica em fazer uma análise do texto em uma perspectiva dinâmica, que é fazer uma análise léxico-gramatical progressiva de oração em oração, observando como escolhas em determinados pontos dos subsistemas de ações condicionam escolhas superiores. Segundo Maththiessen (1995), a LSF oferece um arcabouço teórico abrangente que contempla esse fenômeno chamado logogênese. A partir desse processos, observaremos a construção de metáforas conceptuais baseadas nas escolhas lexicogramaticais do texto.

\section{Procedimentos de análise}

Para que se responda às perguntas de pesquisa, os seguintes procedimentos foram adotados:

a) apresentação dos trechos selecionados;

b) exame do contexto situacional em que ocorre o conto;

INTERLETRAS, ISSN No 1807-1597. V. 9, Edição número 34. Outubro, 2021/ Março de 2022- p.

Dossiê: Estudos de indigenismo, negritude e miscigenação: o (des)cobrimento, colonização e o agora(?) . 
c) análise da parte verbal, segundo a LSF/Avaliatividade (HALLIDAY, 1994, MARTIN, 2004);

d) análise das escolhas lexicais, de acordo com Li (2010), cuja consideração revela a metáfora que percorre o texto.

Foi analisado a capítulo Maria, que evidencia a discriminação e o preconceito racial.

\section{Análise e discussão do conto Maria \\ Contexto situacional}

(a) Campo (assunto): O conto trata da personagem Maria, á o texto "Maria" conta a história de uma empregada doméstica que entra em um ônibus na volta do trabalho, se depara com assaltantes e se assusta ao ver que um deles é o ex-marido, pai de seu filho mais velho.

(b) Relações (interação): A narrativa mescla pensamentos, sentimentos e diálogos entre a personagem e o homem. No meio da ação dos bandidos, eles conversam sobre o filho, a vida que dividiam no passado e ela demonstra que sente saudade do amor daquele ex-companheiro.

(c) Modo (construção do texto): Na narrativa, em meio à ação dos bandidos, eles conversam sobre o filho, a vida que dividiam no passado e ela demonstra que sente saudade do amor daquele ex-companheiro.

\section{Análise e discussão do enunciado verbal}

Analisaremos alguns trechos do texto, extraídos do conto. Como exemplo, mostraremos a análise feita no primeiro parágrafo do conto (trecho 1).

\section{Trecho -1}

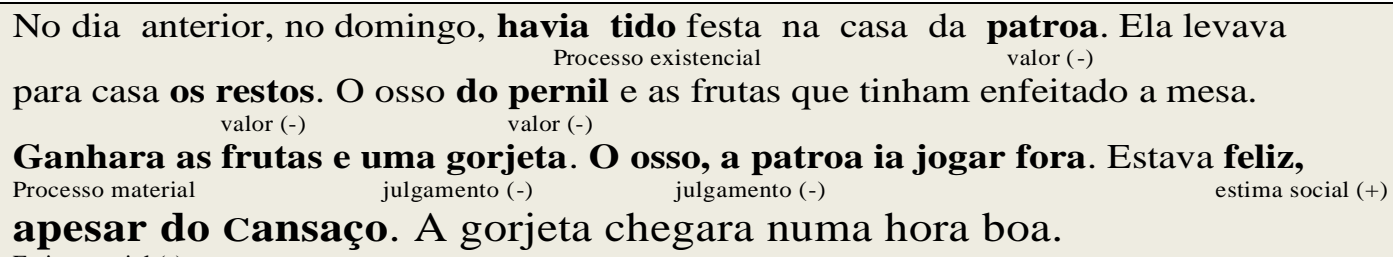

Como se observa na análise o texto "Maria", que conta a história de uma empregada doméstica que ao entrar em um ônibus na volta do trabalho, defronta-se com assaltantes para sua surpresa percebe que um deles é o ex-marido, pai de seu filho mais velho. A narrativa mescla pensamentos, sentimentos e diálogos entre a personagem e o homem.

INTERLETRAS, ISSN $N^{o}$ 1807-1597. V. 9, Edição número 34. Outubro, 2021/ Março de 2022- p.

Dossiê: Estudos de indigenismo, negritude e miscigenação: o (des)cobrimento, colonização e o agora(?) . 
Os trechos selecionados mostram a logogênese do texto que cria no leitor a ideia que de sofrimento da pessoa comum, negra e pobre. É uma história arrebatadora e comovente. O conto relata o sofrimento de uma mãe negra e pobre, que fazia sacrifícios subumanos para cuidar dos filhos.

A história da empregada doméstica faz um paralelo com a nossa sociedade atual, que marginaliza e prejulga as pessoas que não se encaixam nos padrões financeiros, estéticos e culturais. Pode-se observar no trecho 1, a grande presença de, dentro do esquema de avaliativade, de julgamentos negativos e valorizações negativas, o que constrói na cabeça do leitor, vias minimetonímias, as metáforas da empregado do casa como um ser inferiorizado, que para sobreviver e alimentar sua prole, precisa de restos de comidas e frutas, além de gorjetas por serviços extras para obter um renda familiar que complete suas necessidades mais básicas.

\section{CONSIDERAÇÕES FINAIS}

De forma estrutural e sistêmica, a desigualdade é presente na sociedade brasileira em que brancos e negros convivem diariamente com a falta de políticas públicas para o enfrentamento dessa batalha em que se busca a construção de uma sociedade igualitária, justa e com respeito na qual o Estado trace estratégias eficazes para o seu enfrentamento.

Para Li (2020), as escolhas lexicais colocacionalmente, no caso do conto de Evaristo, constroem metáforas dominantes que funcionam com temas organizacionais promovendo um determinado entendimento desse conto.

As expressões metafóricas, as também chamadas, por Li, de minimetonímias, como "facas a laser que cortam a vida" mostra com dor ao leitor para que este considere a crítica aos problemas raciais e à pobreza trazidos pela autora. Essas expressões permitem a metáfora conceptual que orienta a leitura do conto. Nesse caso, podem-se depreender as seguintes metáforas conceptuais:

\section{- NEGRITUDE É CRIMINALIDADE \\ - NEGRITUDE DE É INFERIORIDADE \\ - NEGRITUDE É CULPABILIDADE}

O uso da metáfora proporciona uma vasta gama de palavras e frases que possuem diferentes combinações tornando-se complexa pelo fato de poder ser empregada, ter diversos significados, dando forma e materializando o pensamento humano dentro da cultura que proporciona o entendimento da mensagem, para que e a quem se destina, possibilitando o entendimento no momento da fala, conduzindo a uma metáfora mental. Muitas expressões e conceitos são compreendidos através da metáfora por ela traduzir uma conceitualização abstrata e concreta para ser entendida de forma clara e se objetivar com um repertório integrante da fala do indivíduo.

INTERLETRAS, ISSN No 1807-1597. V. 9, Edição número 34. Outubro, 2021/ Março de 2022- p.

Dossiê: Estudos de indigenismo, negritude e miscigenação: o (des)cobrimento, colonização e o agora(?) . 
Retomando as perguntas de pesquisa (a) e (b) tem-se que, a respeito das escolhas gramaticais, elas confirmam o racismo, discriminação e desigualdade. Observa-se que o uso dos processos materiais do conto propicia uma aproximação do texto com o leitor, causando nele uma indignação nessas escolhas. Já, no caso do papel que a avaliatividade e a metáfora exercem nesse processo, observamos que as metáforas construídas, via minimetáforas, nos remetem à servidão, intolerância racial, culpabilidade, criminalidade e racismo.

\section{REFERÊNCIAS}

As experiências do "SER NEGRO" na sociedade brasileira. Disponível em: https://www.geledes.org.br/as-experiencias-do-ser-negro-na-sociedade-brasileira/. Acessada em 03 AGO 2021.

A História da Escravidão Negra no Brasil. Disponível em: https://www.geledes.org.br/historia-da-escravidao-negra-brasil /. Acesso 29 JUL 2021. BRAIT, Beth. Língua e literatura. S.P. Ed. Contexto, 2013.

BRASIL. [Constituição (1988)]. Constituição da República Federativa do Brasil de 1988. Artigo $3^{\circ}$. Brasília, DF: Senado Federal. Disponível em: http://www.senado.leg.br/atividade/const/con1988/con1988_04.06.1998/art_3_asp. Acesso 29 JUL 2021.

BRASIL, Escravidão no. Disponível em: https://pt.wikipedia.org/wiki/Escravid\%C3\%A3o_no_Brasil. Acessada em 23 AGO 2021.

Cadernos Negros 40 anos. Vários autores. Cadernos Negros 13, São Paulo: Quilombhoje, 1990. Disponível em: https://www.quilombhoje.com.br/site/cadernos-negros . Acessado em 23 AGO 2021.

Conceição Evaristo é a homenageada do Enem 2018. Disponível em: https://agenciabrasil.ebc.com.br/educacao/noticia/2018-11/conceicao-evaristo-ehomenageada-do-enem-2018 . Acessada em 03 AGO 2021.

Conceição Evaristo: 'A literatura está nas mãos de homens brancos'. Disponível em: https://www.correiobraziliense.com.br/app/noticia/diversao-e-

arte/2018/07/15/interna_diversao_arte,694873/entrevista-conceicao-evaristo.shtml .

Acessada em 23 AGO 2021.

EVARISTO, Conceição. Dados Biográficos. Disponível em: http://www.letras.ufmg.br/literafro/autoras/188-conceicao-evaristo.Acessada em 03 AGO 2021.

INTERLETRAS, ISSN N $N^{o}$ 1807-1597. V. 9, Edição número 34. Outubro, 2021/ Março de 2022- p.

Dossiê: Estudos de indigenismo, negritude e miscigenação: o (des)cobrimento, colonização e o agora(?) . 
Conceição Evaristo e oficialmente candidata Academia Brasileira de Letras. Disponível em: $\quad$ http://www.letras.ufmg.br/literafro/noticias/1062-conceicao-evaristo-eoficialmente-candidata-a-academia-brasileira-de-letras . Acessada em 03 AGO 2021.

EVARISTO, Conceição. Ela seria a primeira escritora negra da Academia Brasileira de Letras. Disponível em: https://theintercept.com/2018/08/30/conceicao-evaristo-escritoranegra-eleicao-abl/ . Acessada em 23 AGO 2021.

EVARISTO, Conceição. Escrevivência, memória, subjetividade e poeticidade são conceitos-chave da obra de Conceição Evaristo. Disponível em: https://www.todoestudo.com.br/literatura/conceicao-evaristo. Acessada em 23 AGO 2021.

Conceição Evaristo: Escritora, professora e ativista brasileira. Disponível em: https://www.ebiografia.com/conceicao_evaristo/ . Acessada em 23 AGO 2021.

CONCEIÇÃO Evaristo. In: ENCICLOPÉDIA Itaú Cultural de Arte e Cultura

Brasileiras. São Paulo: Itaú Cultural, 2021. Disponível em:

<http://enciclopedia.itaucultural.org.br/pessoa6851/conceicao-evaristo. Acesso em: 27

de Jan. 2021. Verbete da Enciclopédia. ISBN: 978-85-7979-060-7

Conceição Evaristo: "Não leiam só minha biografia. Leiam meus textos". Disponível em: https://www.brasildefato.com.br/2018/11/20/conceicao-evaristo-nao-leiam-so-minhabiografia-leiam-meus-textos . Acessada em 03 AGO 2021.

Conceicao-evaristo-se-emociona-ao-falar-de-marielle-o-vazio-esta-ai. Disponível em: https://agenciabrasil.ebc.com.br/geral/noticia/2018-07/conceicao-evaristo-se-emocionaao-falar-de-marielle-o-vazio-esta-ai . Acessada em 23 AGO 2021;

Conceição Evaristo: uma escritora popular.. Disponível em: https://biblioo.info/entrevista-conceicao-evaristo. Acessada em 23 AGO 2021.

Conceição Evaristo: biografia, principais obras. Disponível em : https://brasilescola.uol.com.br/literatura/conceicao-evaristo.htm . Acessada em 23 AGO 2021.

Conheça a história do movimento negro no Brasil. Disponível em: https://guiadoestudante.abril.com.br/blog/atualidades-vestibular/conheca-a-historia-domovimento-negro-no-brasil /.Acessada em 03 AGO 2021.

Covid-19: comunicação é chave para mitigar abandono. Disponível em: https://observatoriodeeducacao.institutounibanco.org.br/em-debate/conteudomultimidia/detalhe/evasao-e-covid-19-comunicacao-e-chave-para-tentar-impedir-oaumento . Acesso 29 JUL 2021.

INTERLETRAS, ISSN N $N^{o}$ 1807-1597. V. 9, Edição número 34. Outubro, 2021/ Março de 2022- p.

Dossiê: Estudos de indigenismo, negritude e miscigenação: o (des)cobrimento, colonização e o agora(?) . 
Desigualdade racial na educação brasileira: um Guia completo para entender e combater essa realidade. Disponível em:

https://observatoriodeeducacao.institutounibanco.org.br/em-debate/desigualdade-racialnaeducacao. Acessada em 03 AGO 2021.

Desigualdade racial no Brasil: uma realidade atual https://www.politize.com.br/equidade/blogpost/desigualdade-racial-no-brasil/ .Acesso 29 JUL 2021.

EVARISTO, Conceição. Disponível em: https://pt.wikipedia.org/wiki/Concei\%C3\%A7\%C3\%A3o_Evaristo. Acessada em 23 AGO 2021.

Olhos d'Água. Rio de Janeiro: Pallas: Fundação Biblioteca Nacional, 2016. $\left(19^{\mathrm{a}}\right)$ Festa Literária de Paraty. Disponível em: https://www.flip.org.br/homenageados/ Acessada em 23 AGO 2021.

FONSECA, Elienai. et al. Desigualdade Racial, Preconceito e Discriminação no Âmbito Escolar. Faculdade de Ciências da Saúde. Curso de Serviço Social. UNIVAP. Disponível em: http://www.inicepg.univap.br/cd/INIC_2010/anais/arquivos/0038_0019_01.pdf . Acessada em 03 AGO 2021.

GOES, Emanuelle F.; RAMOS, Dandara O.; FERREIRA, Andrea J. F. Desigualdades raciais em saúde e a pandemia da Covid-19. Trabalho, Educação e Saúde, Rio de Janeiro, v. 18, n. 3, 2020, e00278110. DOI: 10.1590/1981-7746-sol00278 Disponível em: https://www.scielo.br/j/tes/a/d9H84fQxchkfhdbwzHpmR9L/?lang=pt.Acesso 29 JUL 2021;

HALLIDAY, M. A. K. An introduction to systemic-functional grammar. Londres: Edward Arnold, 1985; 1994; 2004.

HERING, Rosana. Desigualdades raciais no Brasil: síntese de indicadores e desafios no campo das políticas públicas. Caderno de Saúde Pública, Rio de janeiro, 18 (Suplemento): p. 57-65, 2002. Disponível em: https://www.scielo.br/j/csp/a/sqxP3HJB58RwMKVHNPCdNyw/?lang=pt. Acesso 29 JUL 2021.

HOLLOWAY, I. Basic Concepts for qualitative research. Londres: Blackwell Science, 1997.

IBGE. INSTITUTO BRASILEIRO DE GEOGRAFIA E ESTATÍSTICA. Desigualdades sociais por cor ou raça no Brasil. Rio de Janeiro: IBGE, 2019. Disponível em: https://bit.ly/3zwwiIF.

INTERLETRAS, ISSN N $N^{o}$ 1807-1597. V. 9, Edição número 34. Outubro, 2021/ Março de 2022- p.

Dossiê: Estudos de indigenismo, negritude e miscigenação: o (des)cobrimento, colonização e o agora(?). 
IBGE. INSTITUTO BRASILEIRO DE GEOGRAFIA. Síntese de indicadores sociais: uma análise das condições de vida da população brasileira. Rio de Janeiro: IBGE, 2019. Disponível em: https://biblioteca.ibge.gov.br/index.php/bibliotecacatalogo?view=detalhes\&id=2101678 . Acesso 29 JUL 2021.

LAKOFF, George \& Mark JOHNSON. Metaphors We Live By. Chicago: The University of Chicago Press, 1980.

LAKOFF, G. The contemporary theory of metaphor. In: ORTONY A. Metaphor and thought. Cambridge: Cambridge University Press, 1993.LAKOFF, G.; JOHNSON, M. Metaphor We Live By. Chicago: Chicago University Press, 1980.

LI, J. Transitivity and lexical cohesion: Press representations of a political disaster and its actors. Journal of Pragmatics, v.42, n.12, p. 3444-3458, 2010.

MARTIN, J.R. Beyond Exchange: APPRAISAL Systems in English. In Susan Hunston \& Geoff Thompson (eds.), Evaluation in Text - Authorial Stance and the Construction of Discourse. Oxford: Oxford University Press, 2000.

MARTIN, J. R.; WHITE, P.R.R. The Language of Evaluation:appraisal in English. Londres: Palgrave. 2005.

MATTHIESSEN, C. M. I. M. Lexicogrammatical cartography: English systems. Sidney: Macquarie University. 1995.

Ocupação Conceição Evaristo. Becos da memória. Disponível em: https://www.itaucultural.org.br/ocupacao/conceicao-evaristo/becos-da-memoria.

Acessado em 03 AGO 2021.

OLIVEIRA E PAIVA, Vera Lúcia Menezes. A metonímia como processo fractual multimodal. Veredas online-temática, PPG Linguística/UFJF, nº 1, p. 07-19, 01/2010.

OLIVEIRA, Luiz Henrique Silva de. Escrevivência em Becos da memória, de Conceição Evaristo. IN: Revista Estudos Feministas. vol.17 no.2 Florianópolis May/Aug. 2009. Disponível em: http://dx.doi.org/10.1590/S0104-026X2009000200019. Acesso em: 27 jun. 2016.

"O momento presente pede novas narrativas, diz Conceição Evaristo, homenageada no Enem 2018" Disponível em: https://g1.globo.com/educacao/enem/2018/noticia/2018/11/06/o-momento-presentepede-novas-narrativas-diz-conceicao-evaristo-homenageada-no-enem-2018.ghtml. Acessada em 03 AGO 2021.

SARDINHA, Tony Berber. Metáfora. São Paulo: Editora Parábola, 2007.

INTERLETRAS, ISSN N $N^{o}$ 1807-1597. V. 9, Edição número 34. Outubro, 2021/ Março de 2022- p.

Dossiê: Estudos de indigenismo, negritude e miscigenação: o (des)cobrimento, colonização e o agora(?). 
SILVA, Augusto Soares da e LEITE, Jan Edson Rodrigues. 35 anos de Teoria da Metáfora Conceptual: Fundamentos, problemas e novos rumos. Revista Investigações/ UFPE, $\quad n^{\circ} \quad 2, \quad$ Vol. 28, Julho/2015. Disponível em: https://periodicos.ufpe.br/revistas/INV/index.

SILVA, Simone Rezende. A trajetória do negro no Brasil e a Territorialização quilombola no ambiente florestado atlântico. Tese (Doutorado Geografia Física) - Universidade de São Paulo. São Paulo. 2008. Disponível em: http://www3.ufrb.edu.br/olharessociais/wpcontent/uploads/A-trajetoria-do-negro-no-Brasil.pdf.Acessada em 23 AGO 2021.

VIAN JR, Orlando. O sistema de avaliatividade e os recursos para gradação em língua portuguesa: questões terminológicas e de instanciação. Revista DELTA, v. 25, n. 1, p.99-129, 2009.

* Mestranda do Programa de Pós-Graduação do Curso de Letras da FACALE - Faculdade de Letras e Comunicação da Universidade Federal da Grande Dourados (UFGD). E-mail: denivelascocarioca@yahoo.com.br. http://orcid.org/0000-0001-6958-1286

** Orientador e Professor Doutor do Programa de Pós-Graduação do Curso de Letras da FACALE Faculdade de Letras e Comunicação da Universidade Federal da Grande Dourados (UFGD). E-mail: marcelosaparas@uol.com.br. https://orcid.org/0000-0002-9924-8369

INTERLETRAS, ISSN N 1807-1597. V. 9, Edição número 34. Outubro, 2021/ Março de 2022- p.

Dossiê: Estudos de indigenismo, negritude e miscigenação: o (des)cobrimento, colonização e o agora(?) . 